Du texte à la scène : langages du théâtre

\title{
À propos de la mise en scène de Roméo et Juliette à Nantes par Yves Goulais
}

Yves Goulais

\section{(2) OpenEdition}

\section{Journals}

\section{Édition électronique}

URL : http://journals.openedition.org/shakespeare/486

DOI : 10.4000/shakespeare.486

ISSN : 2271-6424

Éditeur

Société Française Shakespeare

Édition imprimée

Date de publication : 1 novembre 1983

Pagination : 272-273

Référence électronique

Yves Goulais, «À propos de la mise en scène de Roméo et Juliette à Nantes par Yves Goulais », Actes des congrès de la Société française Shakespeare [En ligne], 4 | 1983, mis en ligne le 01 janvier 2007, consulté le 02 mai 2019. URL : http://journals.openedition.org/shakespeare/486 ; DOI : 10.4000/ shakespeare.486 
SOCIETE FRANÇAISE SHAKESPEARE

Actes du Congrès 1982

\section{DU TEXTE A LA SCENE : Langages du Théâtre}

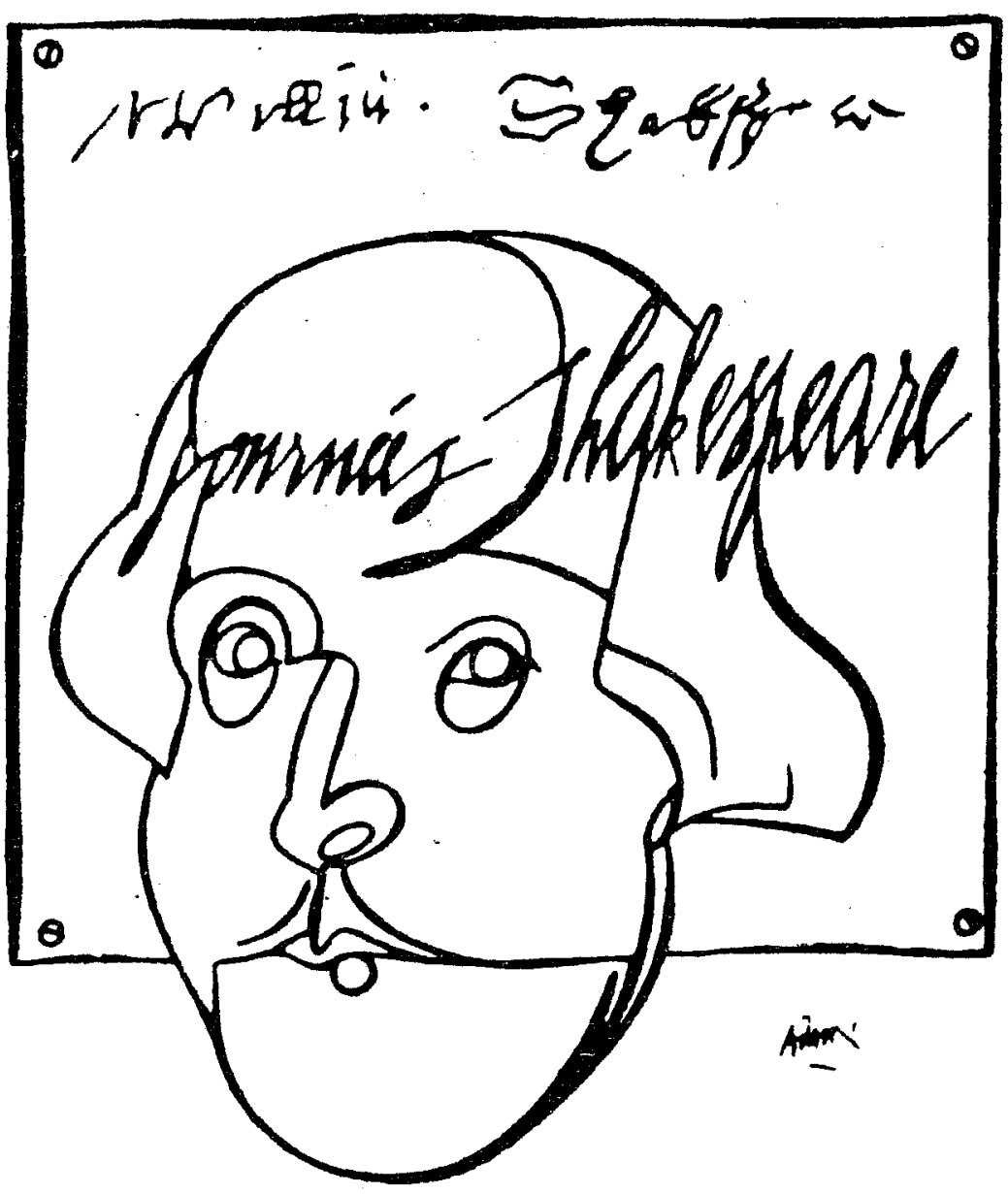

DiRecteur de la publication M.T. Jones - Davies

Publié avec le concours du Centre National de la Recherche Scientifique

JEAN TOUZOT Libraire - Editeur

38 , rue Saint-Sulpice 75278 PARIS CEDEX 061983 


\section{A PROPOS DE LA MISE EN SCENE DE ROMEO ET JULIETTE A NANTES PAR YVES GOULAIS *}

Mettre en scène Roméo et juliette, c'est d'abord retrouver le drame de Shakespeare derrière une certaine dégénérescence du my the vers l'anecdotique et ses clichés, c'est-à-dire éliminer toutes les scories accumulées par d'innombrables adaptations. Il est nécessaire de mettre à nu les forces vives et permanentes du drame à partir d'un texte respectueux de l'original, il faut trouver un fil conducteur, développer de simples indices, grossir certains aspects, en laisser d'autres dans l'ombre, car on doit tenir compte de l'évolution des conventions, aussi bien celles du théâtre que celles de l'amour. Le metteur en scène est pris au double piège de la fidélité et du choix, il lui faut à la fois suivre et choisir.

J'ai donc voulu distinguer deux plans différents : le quotidien et l'extraordinaire. Le quotidien, c'est l'ennui, la haine, les choses qui sont des choses, c'est la vie domestique, la vie publique, c'est le lieu où l'on joue à jouer; tout cela se passe sur la scène traditionnelle. Je me suis attaché à rendre le réalisme onirique avec le bal masqué, je l'ai vuavec des yeux d'enfant, peut-être ceux de Juliette avant qu'elle ne plonge dans le monde autrement inquiétant des adultes. Pour moi, le bal est un univers animalier, peuplé des souvenirs de Lewis Carroll, où temps, espace et dimensions sont remis en question. Les extravagances du bal permettent une citation du passé, une référence au temps de Shakespeare, sans pour autant tomber dans la rétrospective ou la caricature, d'ailleurs les autres costumes sont intemporels. Un autre aspect du réalisme onirique est le tableau des pestiférés (acte $V$, scène ii), image implicite dans le texte; celle-ci; délibérément grossie, devient une

\footnotetext{
* 18 représentations seront données à Nantes en décembre 1982 à la Maison de Doulon et au Grand Auditorium du Conservatoire de Région.
} 
allégorie de la malédiction qui frappe Vérone, anticipe le dénouement, thêâtralise la culpabilité et apporte une solution plus crédible que la réconciliation des Montaigues et des Capulets avec leur statue d'or pur.

Face à la scène traditionnelle et située au milieu du public, «la folle gabarre», sculpture monumentale faite de troncs d'arbres délavés et de peaux, représente l'espace de l'imaginaire, de l'extrême bonheur et de l'extrême malheur. C'est là que se déroulent les grands moments lyriques, du désir, de l'amour, de la séparation et de la mort. C'est là le moyen d'ancrer la poésie dans un espace scénique. C'est une proposition, une provocation peutêtre, c'est un support pour les images et les métaphores qui laisse aux spectateurs la liberté d'imaginer, alors que $œ$ qui se passe sur le plateau traditionnel impose une lecture plus directive.

Cette nouvelle mise en scène de Roméo et Juliette est ambitieuse car en plus de nombreux acteurs et figurants, elle intègre une importante musique de scène originale qui commente et accompagne l'action. Associer des moyens d'expression divers (décors, sculpture, musique), associer des comédiens amateurs et professionnels dans un lieu théâtral inhabituel est à la fois un risque et un défi. 